\title{
Overview of Steel Bridges Containing High Strength Steel
}

\author{
Oskar Skoglund $^{1}$ (D) John Leander ${ }^{1} \cdot$ Raid Karoumi $^{1}$
}

Received: 20 May 2019 / Accepted: 21 May 2020 / Published online: 9 June 2020

(c) The Author(s) 2020

\begin{abstract}
The use of high strength steel has the potential to reduce the amount of steel used in bridges and thereby, facilitate a more sustainable construction. A survey of existing bridges built using high strength steel is presented in this paper with emphasis on the Swedish bridge stock. The survey aimed at identifying the steel grades that were used and where in the cross-section they have been used. A case study on the influence of fatigue shows that today's regulations make it more difficult to use high strength steel in comparison to previous regulations.
\end{abstract}

Keywords High strength steel $\cdot$ Steel bridges $\cdot$ Composite bridges $\cdot$ Fatigue assessment $\cdot$ Hybrid girders

\section{Introduction}

The use of high strength steel (HSS) for bridges has increased over the past decades and countries such as Japan has a long tradition of building with HSS (Miki et al. 2002). Meanwhile, the trend in Europe is not as strong and the most commonly used steel grade is S355 (Johansson et al. 2008); where $\mathrm{S}$ stands for structural steel and 355 is the yield strength in MPa. In this paper HSS is referred to as a steel with a yield strength of $500 \mathrm{MPa}$ or higher. An increase in steel grade allows for a more slender and aesthetic design that often leads to savings in cost and material. The cost and material savings are highly dependent on to what degree the material is being utilized and the most economical solution is often achieved by using hybrid girders; a hybrid girder is a welded girder that contains different steel grades for the flanges and web, which enables the designer to optimize the utilization ratio of each individual plate. However, when the static strength of the structure is not the decisive design factor, but rather the deflection, dynamic properties,

Oskar Skoglund

oskarsko@kth.se

John Leander

john.leander@byv.kth.se

Raid Karoumi

raid.karoumi@byv.kth.se

1 Division of Structural Engineering and Bridges, KTH Royal Institute of Technology, Brinellvägen 23, 10044 Stockholm, Sweden instability phenomena or fatigue resistance, the advantage of HSS becomes questionable; where fatigue usually governs the resistance of HSS bridges. The fatigue strength of steel bridges is usually limiting the use of HSS for the following reasons: for a lower material usage, which is associated with using HSS, the stress range will increase and at the same time for welded steel structures, in the as-welded condition, the fatigue strength is not affected by an increase in yield strength of the material, according to the design codes (European Committee for Standardization 2008; Boverket 1994).

Several cost studies on HSS and hybrid girders have been made. In Mela and Heinisuo (2014), single structural members were studied and it was concluded that after a certain threshold of span length and load magnitude hybrid girders using HSS became profitable. The savings in cost of the steelwork were in the region of 5-10\%. A cost evaluation of an arch bridge was studied in Park et al. (2016) and by partly using HSS, $12.1 \%$ of the total bridge cost could be reduced. In Horton et al. (2002) and Barker and Schrage (2000), a series of continuous two span highway bridges were studied and by using hybrid girders compared to homogeneous, $13 \%$ and $11 \%$ of the steelwork cost could be saved, in each study respectively.

Fatigue assessment according to Eurocode is given in EN 1993-2 and 1993-1-9, and states, in principle, two different verification formats; the damage equivalent method and the cumulative damage method. The damage equivalent method, allows the designer to represent the real traffic acting on the bridge in a simplified way by adjusting 
the stress range produced by the vehicle given in the code by the use of $\lambda$-factors. The $\lambda$-factors, are controlled by the influence line, traffic volume, lifespan of the bridge and the influence of more than one load acting on the bridge. Meanwhile, using the cumulative damage method puts more effort on the designer and requires the use of cycle counting methods. Depending on verification format and whether unlimited fatigue life or not is to be controlled for, EN 1993-2 specifies five different fatigue load models for road bridges, all of which are calibrated against traffic measurements as to resemble typical traffic conditions on European roads (Sedlacek et al. 2008; Croce 2001). Fatigue load model (FLM) 1 and 2 are used to verify for an unlimited fatigue life and together with FLM 3 the fatigue life is verified with the damage equivalent method. For the cumulative damage method FLM 4 or 5 should be used. FLM 4 consists of five vehicle types stated in EN 1993-2. Meanwhile, FLM 5 is used for more accurate fatigue verification and is based on direct application of actual traffic data measurements. FLM 5 is often applied to bridges with unusual traffic, suspension and cable-stayed bridges and/ or important existing bridges. Furthermore, there are two design strategies according to the Eurocode; the safe life approach and the damage tolerant approach. Both of these strategies reaches a required reliability level by adjusting the design load and design stress range by safety factors, where the safe life approach results in a more conservative estimation of the fatigue life compared to the damage tolerant method. The difference between the two strategies is that in the safe life approach regular inspections that can detect fatigue damage is not required. In Sweden, Eurocode has been the governing standard since 2011 and for steel structures it was preceded by Boverkets handbok om stålkonstruktioner (BSK).

In this paper, a survey of existing steel girder bridges constructed in Sweden between 1990 and 2015 is presented. The objective of the survey was to study how common different steel grades are and how they have been used in the cross-section for different segments along the bridge. A fatigue assessment was performed for a few of the bridges containing HSS, both with today's standard and with the standard governing at the time of design and construction of the specific bridges.

The objectives of this study are tied together with an overall aim of identifying the difficulties and the possible economical and environmental benefits of building with HSS, as well as finding solutions to the fatigue issue.

The outline of this paper is as follows. In Sect. 2, a few examples of where HSS has been applied in USA, Japan and Europe are given together with a description of the survey of the Swedish bridges. In the subsequent section the results of the survey are given. For the HSS bridges found in the survey, a case study was performed with respect to fatigue and presented in Sect. 4. In the last two sections the discussion and conclusion of the results are given.

\section{Overview of Bridge Structures}

\subsection{HSS in USA}

High-performance steel (HPS) was developed in 1992 and was initiated by the U.S. Federal Highway Administration with the aim of developing a steel with higher strength, improved weldability and higher toughness. These steels come in 345, 485 and $690 \mathrm{MPa}(50,70$ and $100 \mathrm{ksi})$ minimum yield strength and with "weathering" characteristics. The specification for chemical composition and the upper limit for the content of alloying elements are similar to those given in EN 10025-4 (European Committee for Standardization 2004a), and EN 10025-6 (European Committee for Standardization 2004b). More information about HPS can be found in Günther et al. (2005) and Bjorhovde (2004). The first bridge in USA to incorporate HPS 100 was built in 2003, along Highway N-2 crossing Interstate 80, in Nebraska. The bridge consists of two spans of $42 \mathrm{~m}$ each and the concrete deck is carried by three box girders, which are made of HPS 100. The original design with HPS 70 in the top flange and HPS 50 in bottom flange and web was proved to be the most economical design. However, HPS 100 had just become available on the market, and to show that fabrication and construction could proceed in a similar way as with other types of steel, the latter design was used. More information is given in Azizinamini et al. (2004). Another example of where HPS 100 has been incorporated is for a two span steel girder bridge along route SR 1102 crossing I-77, built in 2009 in North Carolina. The concrete deck is carried by nine steel girders, each girder consisting of three segments ( $35.7 \mathrm{~m}, 18.2 \mathrm{~m}$ and $35.7 \mathrm{~m})$. The segment located over the intermediate support is built with HPS $100 \mathrm{~W}$ for the flanges and HPS $70 \mathrm{~W}$ for the web; the other two segments are made entirely out of HPS $70 \mathrm{~W}$. See construction report given in Chen et al. (2001) for more information.

\subsection{HSS in Japan}

Japan has a long tradition of using HSS for bridge structures and for many projects steel plates with a yield strength of $800 \mathrm{MPa}$ are used (Miki et al. 2002; Tsujii and Kanno 2010). To overcome the difficulties of welding, fabrication and formability of high strength steels, bridge high performance steel (BHS) was developed and applied in 1996. The alloying content and manufacturing methods are similar to those of HPS (Günther et al. 2005). The Akashi Kaikyo Bridge is the world's longest suspension bridge and completed in 1998. In order to accomplish the large spans the 
dead weight was needed to be reduced, which was achieved by incorporating $800 \mathrm{MPa}$ steel in the truss system (Miki et al. 2002). Another example is the Tokyo gate bridge where BHS with $500 \mathrm{MPa}$ was used in the majority of the truss system (Yoneyama and Fujii 2015).

\subsection{HSS in Europe}

The Nesenbachtal bridge completed in Germany in 2000, is a five span continuous road bridge mainly built with S355 (1341 tonnes) but also with S690 (284 tonnes) at the supports. The concrete slab is supported by a lattice girder structure made out of tubular sections, which in turn is supported by steel columns (Johansson et al. 2008).

\subsection{Survey of Swedish Bridges}

To study the trend of using different steel grades for bridges, a survey of 489 steel girder bridges constructed in Sweden between 1990 and 2015 was performed. The trend of using HSS was determined by studying the main load carrying system of the most severely loaded span and also, for the multi-span bridges, the most severely loaded support. The study covers segments of the bridge and for these segments the steel grade was noted for all individual plates. All structural drawings were accessed through the Swedish bridge management system BaTMan (Trafikverket 2004).

Out of the 489 bridges, 249 are multi-span, 432 are road and 57 are railway bridges. Out of the road bridges, 412 are steel and concrete bridges with composite action, 18 bridges are without composite action, 1 is a pure steel bridge and 1 is a steel and timber bridge. Out of the railway bridges, 26 are steel and concrete bridges with composite action, 8 bridges without composite action and 23 steel bridges. The number of bridges built per year is shown in Fig. 1 .

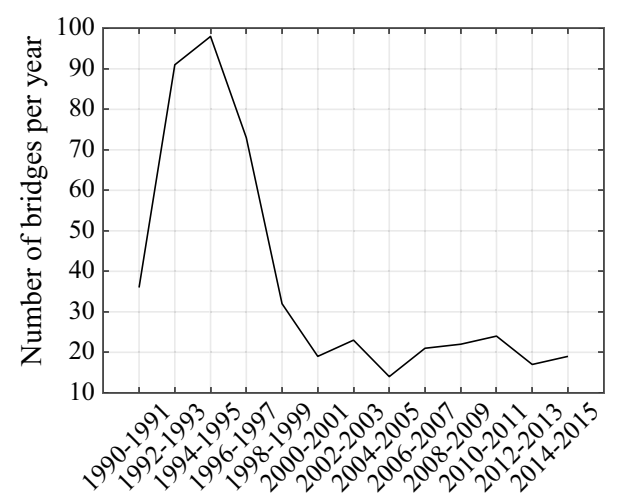

Fig. 1 Number of steel girder bridges available at Trafikverket (2004) and constructed in Sweden during the interval of 1990-2015

\section{Result from Overview of Bridge Structures}

Out of the 489 steel girder bridges the lowest steel grade used was S355 for road bridges and S275 for railway bridges. In general road bridges were built with a higher grade of steel compared to railway bridges. The highest steel grade used for each bridge, as a percentage of all road and railway bridges respectively, can be studied in Fig. 2. In total seven bridges were built using HSS, four using S690 (built 1996) and three using S500 (built between 1990 and 1993).

The trend of using higher steel grade has increased since the beginning of the 90s and the most common way of composing the cross-section is by placing the steel with the highest grade in the lower flange. Least common is to place the higher strength material in the web. The average yield strength for all individual plates and for all road bridges built in the given intervals are presented in Fig. 3a, b for a section over the span and over the support respectively.

The trend of using hybrid girders has increased since the mid-90s and for bridges designed today, roughly $80 \%$, use hybrid girders. The number and percentage of bridges using hybrid girders are depicted in Fig. 4; the percentage is set in relation to bridges using a steel grade above S275 and S355 for railway and road bridges respectively.

The relation between span length and highest steel grade used was also studied. However, no correlation could be observed.

\section{Case Study on High Strength Steel Bridges}

From the material collected, four single span composite steel and concrete bridges using S690 has been built. All four bridges were designed in a similar way and by the same consultant company. Table 1 gives the theoretical annual average daily traffic (AADT) and span length for each bridge together with the road number and county where the bridge is located. The AADT is taken from Trafikverket (2017).

In the following sections, cross-sectional data for the bridge along road 977 crossing Röån is given together with the fatigue verification format in Eurocode and in BSK 94. BSK 94 was the governing standard at the time when these bridges were designed and built.

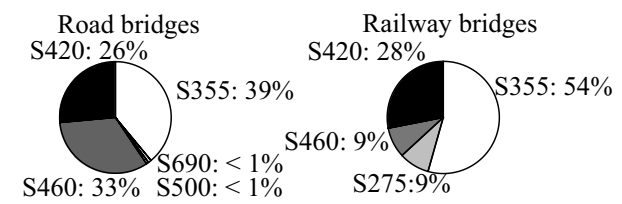

Fig. 2 Percentage of bridges using S275, S355, S420, S460, S500 and $\mathrm{S} 690$ respectively, as the highest steel grade 
Fig. 3 Average yield strength of the web and upper and lower flanges. a For a segment over the span; $\mathbf{b}$ for a segment over the support (a)

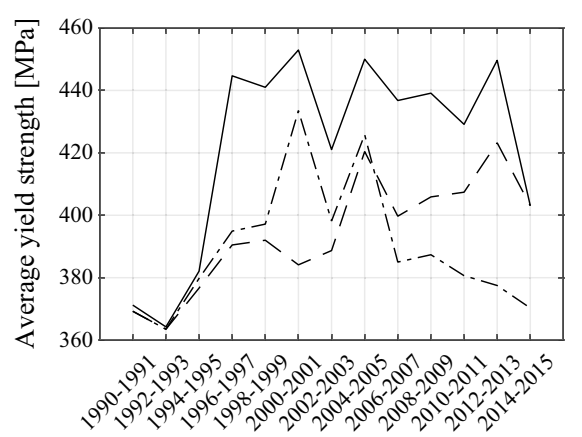

(b)

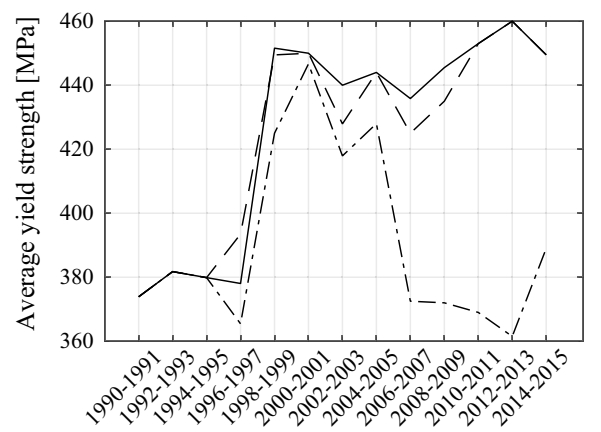

Lower flange --- Upper flange ----- Web

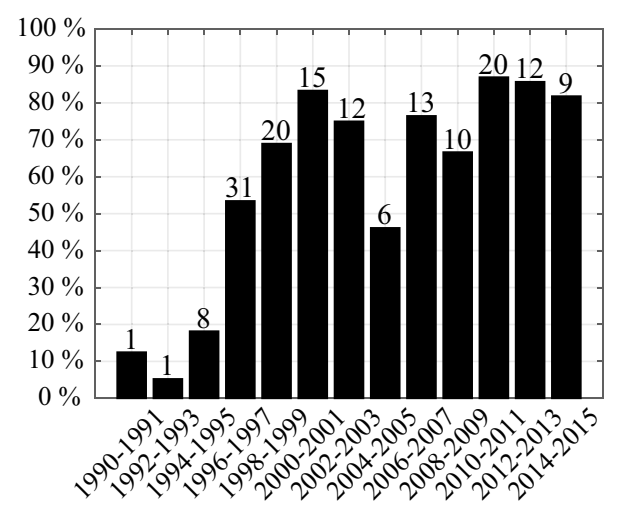

Fig. 4 Percentage and amount of bridges constructed in the given intervals that use hybrid girders

Table 1 Road number, county, annual average daily traffic and bridge span length

\begin{tabular}{llcl}
\hline Road number & County & AADT & Span length $(\mathrm{m})$ \\
\hline 976 & Västernorrland & 68 & 25 \\
949 & Västernorrland & 70 & 22 \\
977 & Västernorrland & 144 & 27 \\
531 & Jämtland & 265 & 25.6 \\
\hline
\end{tabular}

\subsection{Bridge Along Road 977}

The cross-sectional data was taken and reproduced from the structural drawings, obtained from Trafikverket (2004). The concrete deck, with quality K40 (here taken as C30/37), is carried by two steel girders with the length of $27 \mathrm{~m}$ and the bridge was analysed as simply supported. The girder consists of three segments with two different dimensions, where segment 1 is the segment closest to the support and segment 2 is covering the mid-span; see Fig. 5a. The cross-section of the bridge is given in Fig. 5b.

To simplify the problem, the concrete deck was assumed to have a uniform thickness; the width and the thickness of the deck were set to $7.65 \mathrm{~m}$ and $0.27 \mathrm{~m}$, respectively. The width of the carriageway was set to $6.85 \mathrm{~m}$, which makes room for two lanes (of $3 \mathrm{~m}$ each). The bridge has four sets of horizontal bracings, two positioned at the supports and two position $9 \mathrm{~m}$ from the supports. The horizontal bracing positioned $9 \mathrm{~m}$ from the support is presented in Fig. 6 .

In Table 2 the girder dimensions and steel grade for the individual plates are given, following the labelling in Fig. 6. (a)

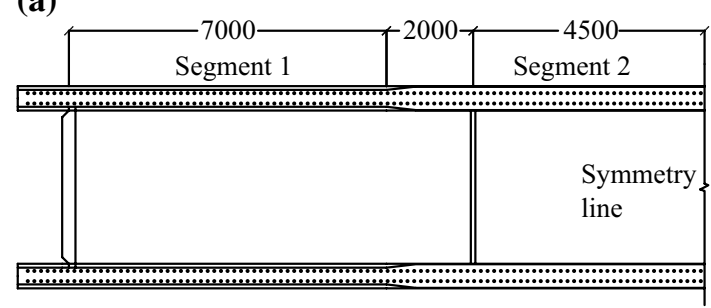

(b)

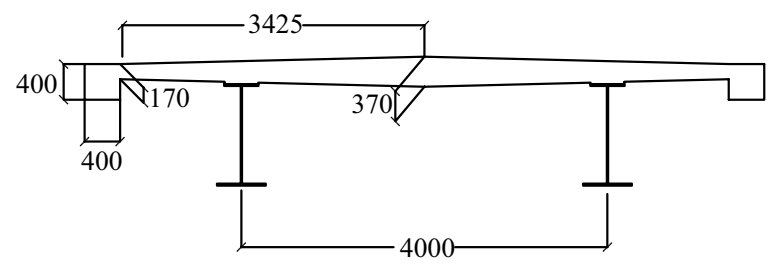

Fig. 5 Bridge along road 977 [units: (mm)]. a Overview of the girder lengths and position of horizontal bracings; b cross-section of the composite bridge 


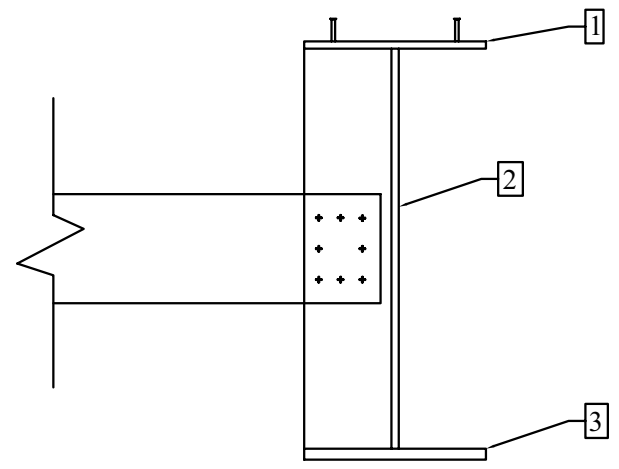

Fig. 6 Horizontal bracing

Table 2 Dimensions and steel grade

\begin{tabular}{llll}
\hline Label & Size $(\mathrm{mm})$ & & Steel grade \\
\cline { 2 - 3 } & Segment 1 & Segment 2 & \\
\hline 1 & $20 \times 380$ & $20 \times 530$ & S355 \\
2 & $14 \times 1106$ & $13 \times 1100$ & $\mathrm{~S} 460$ \\
3 & $22 \times 550$ & $30 \times 550$ & $\mathrm{~S} 690$ \\
\hline
\end{tabular}

\subsection{Fatigue Assessment According to Eurocode}

The damage equivalent method with fatigue load model 3 (FLM 3) was used to verify the fatigue resistance. The fatigue assessment procedure is given in EN 1993-2 (European Committee for Standardization 2006), and defined as:

$\gamma_{\mathrm{Ff}} \Delta \sigma_{\mathrm{E} 2} \leq \frac{\Delta \sigma_{\mathrm{c}}}{\gamma_{\mathrm{Mf}}}$

where $\Delta \sigma_{\mathrm{E} 2}$ is the equivalent stress range and $\Delta \sigma_{\mathrm{c}}$ is the fatigue strength, both corresponding to 2 million cycles. The fatigue strength depends on the detail category and is given in EN 1993-1-9 (European Committee for Standardization 2008). The partial safety factor for fatigue loading, $\gamma_{\mathrm{Ff}}$, was set to 1.0 and the partial safety factor for fatigue resistance, $\gamma_{\mathrm{Mf}}$, was set to 1.0 when considering studs in shear, otherwise it was set to 1.35 according to the safe life approach. The equivalent stress range, $\Delta \sigma_{\mathrm{E} 2}$, is calculated as:

$\Delta \sigma_{\mathrm{E} 2}=\lambda \phi \Delta \sigma$ where $\lambda$ is a damage equivalence factor, $\phi$ is a damage equivalent impact factor and $\Delta \sigma$ is the stress range. The stress range is defined as the algebraic difference between the maximum and the minimum stress, obtained from two possible load positions. The factor $\phi$ was set to 1.0 according to EN 1994-2 (European Committee for Standardization 2005), and $\lambda$ was determined according to EN 1993-2 (European Committee for Standardization 2006), and EN 1994-2 (European Committee for Standardization 2005).

FLM 3, described in EN 1991-2 (European Committee for Standardization 2010), consists of a single vehicle represented by four discrete point loads, see Fig. $7 \mathrm{a}$. The number of heavy vehicles, $N_{\text {obs }}$, per year is given in Table 4.5(n) in European Committee for Standardization (2010) and is depending on the traffic category. According to the Swedish Annex (Trafikverket 2011), an AADT of heavy traffic $\leq 600$ belongs to traffic category 4 , which gives $N_{\text {obs }}=50,000$. The bridges were assumed to have a service life of 100 years. The fatigue resistance was evaluated for four different locations, see Fig. 8 .

Location 1, 3 and 4 were evaluated for longitudinal normal stresses, $\sigma$, with a crack formation perpendicular to the direction of the stresses and location 2 was evaluated for longitudinal shear stresses, $\tau$, at the base of the shear stud. The detail category for each fatigue location is given in column two and three of Table 3 and taken from EN 1993-1-9 (European Committee for Standardization 2008), with $\Delta \sigma_{\mathrm{c}}$ denoting detail category for longitudinal stresses and $\Delta \tau_{\mathrm{c}}$ denoting detail category for shear stresses.

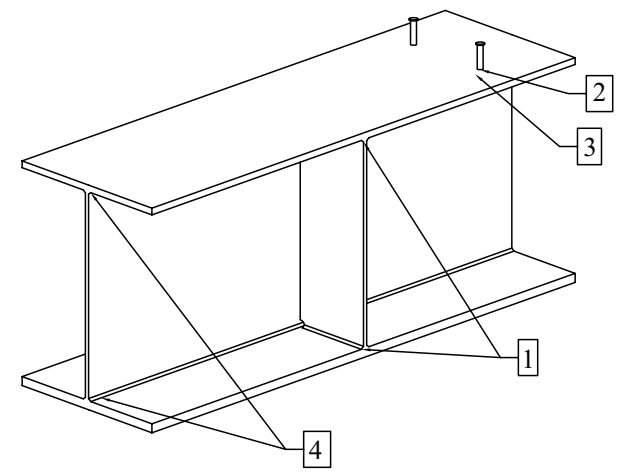

Fig. 8 Fatigue locations that are being studied

(b)

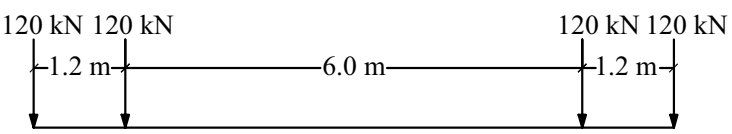

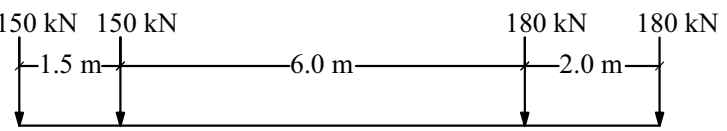

Fig. 7 Load configurations. a FLM 3 according to Eurocode; b equivalent load type 5 according to Vägverket (1994) 
Table 3 Detail category and joint class for each position

\begin{tabular}{llll}
\hline Position & $\Delta \sigma_{\mathrm{c}}(\mathrm{MPa})$ & $\Delta \tau_{\mathrm{c}}(\mathrm{MPa})$ & $\mathrm{C}(\mathrm{MPa})$ \\
\hline 1 & 80 & - & 63 \\
2 & - & 90 & 63 \\
3 & 80 & - & 63 \\
4 & 125 & - & 80 \\
\hline
\end{tabular}

\subsection{Fatigue Assessment According to BSK 94}

The original designs of the bridges were based on Boverkets handbok om stålkonstruktioner (BSK 94). Therefore, the bridges covered in this study were also verified with the old Swedish standard. To evaluate the fatigue resistance, equivalent load type 5 was used; the load configuration is given in Fig. 7b. The fatigue assessment procedure is given in BSK 94 (Boverket 1994), and is defined as:

$\Delta \sigma_{\mathrm{r}} \leq f_{\mathrm{rd}}$

where $\Delta \sigma_{\mathrm{r}}$ is the maximum nominal stress range produced by the load configuration and $f_{\text {rd }}$ is the design fatigue strength. The design fatigue strength, $f_{\text {rd }}$, is calculated as:

$f_{\mathrm{rd}}=\frac{f_{\mathrm{rk}}}{1.1 \gamma_{\mathrm{n}}}$

where $\gamma_{\mathrm{n}}$ is partial safety factor and was set to 1.2 . The characteristic fatigue strength, $f_{\text {rk }}$, for constant amplitude stress range and for less than $5 \times 10^{6}$ load cycles is calculated as:

$f_{\mathrm{rk}}=C\left(\frac{2 \times 10^{6}}{n_{\mathrm{t}}}\right)^{1 / 3}$

where $n_{\mathrm{t}}$ is the number of load cycles and $C$ is the joint class, which is the characteristic fatigue strength corresponding to 2 million cycles.

For an AADT of heavy vehicles $\leq 10,000$ the number of load cycles, $n_{\mathrm{t}}$, is set to $10^{5}$. The joint class $C$, obtained from Boverket (1994), for each of the four locations in Fig. 8, is given in column four of Table 3 and is valid for weld class WB and $n_{\mathrm{t}}=10^{5}$. Location 2 and 3 were verified based on longitudinal normal stresses, which were the same in both cases.

\subsection{Result from Fatigue Evaluation of Existing HSS Bridges}

The design stress range, $\gamma_{\mathrm{Ff}} \Delta \sigma_{E 2}$, and the design fatigue strength, $\Delta \sigma_{\mathrm{c}} / \gamma_{\mathrm{Mf}}$, given within parenthesis, are calculated according to Eurocode and given for each location in Table 4 . Each bridge is identified by its corresponding road number. The table shows that the design stress range is larger than the fatigue strength for locations 1 and 4 indicating an insufficient fatigue resistance.

To achieve a sufficient fatigue resistance for the bridges the fatigue strength of location 1 needs to be improved by $81-66 \%$ and for location 4 by $21-9 \%$.

The maximum stress range, $\Delta \sigma_{\mathrm{r}}$, and the design fatigue strength, $f_{\text {rd }}$, given within parenthesis, are calculated according to BSK 94 and given for each location in Table 5. By comparing the stress range with the fatigue strength, it is evident that fatigue is not decisive for any of the four locations with the BSK fatigue assessment format.

The results presented in Tables 4 and 5 show that the bridges constructed with S690 material during 1996 following the old Swedish regulations, could not have been built following the Eurocodes.

\section{Discussion}

\subsection{Overview of Bridge Structures}

The popularity of a certain steel grade varies from year to year and is mostly depending on the specific consultant company and their way of designing steel bridges. Another reason for this fluctuation is that the steel price is changing and so is the relative difference between the different qualities. Therefore, a certain steel grade might be preferred over another, at a certain time. Furthermore, the availability of the higher grades of steel might have a huge impact. For

Table 4 Fatigue assessment according to Eurocode

\begin{tabular}{lllll}
\hline Bridge & \multicolumn{4}{l}{ Fatigue assessment at location } \\
\cline { 2 - 5 } & 1 & 2 & 3 & 4 \\
\hline 976 & $107(59)$ & $59(90)$ & $4.2(59)$ & $111(92)$ \\
949 & $104(59)$ & $65(90)$ & $3.1(59)$ & $106(92)$ \\
977 & $100(59)$ & $59(90)$ & $2.4(59)$ & $105(92)$ \\
531 & $98(59)$ & $66(90)$ & $2.7(59)$ & $100(92)$ \\
\hline
\end{tabular}

The design stress range and the design fatigue strength, given within parenthesis, are expressed in $\mathrm{MPa}$

Table 5 Fatigue assessment according to BSK

\begin{tabular}{llll}
\hline Bridge & \multicolumn{3}{l}{ Fatigue assessment at location } \\
\cline { 2 - 4 } & 1 & 2 and 3 & 4 \\
\hline 976 & $111(129)$ & $4.4(129)$ & $118(164)$ \\
949 & $106(129)$ & $3.2(129)$ & $111(164)$ \\
977 & $105(129)$ & $2.6(129)$ & $112(164)$ \\
531 & $103(129)$ & $2.9(129)$ & $106(164)$ \\
\hline
\end{tabular}

The design stress range and the design fatigue strength, given within parenthesis, are expressed in $\mathrm{MPa}$ 
these steels to be competitive compared to the conventional steel, S355, the delivery times must be within a reasonable time-scale. The delivery time also changes from year to year and is depending on the consumption; higher consumption usually means shorter delivery time since the mills will keep these steels in their stock.

The use of HSS in the web plate experienced a huge drop after 2005, it could be that the designers realised that it was not optimal due to web-plate buckling and therefore preferred stockier plates with lower yield strength.

\subsection{Fatigue Evaluation of Existing HSS Bridges}

To make HSS a viable option, the fatigue issue must be solved. There are methods to increase the fatigue strength of welded details, especially for steels with high yield strength. Several approaches of weld improvement methods and approaches to increase the fatigue life are given in Günther et al. (2005) and Kirkhope et al. (1999). The hammer peening method has been reported to give among the highest improvement rates of fatigue strength, and usually in the order of $50-200 \%$ (Kirkhope et al. 1999). The recommendations for weld improvement techniques given in Table 3.11 of International Institute of Welding (Hobbacher 2016), states that an improvement of 50\% for steel with a yield strength equal or greater than $355 \mathrm{MPa}$ can be claimed by hammer peening methods. This improvement is only a recommendation and not possible to use when designing according to Eurocode. However, these improvement methods give an indication of what can be gained if weldless joints are manufactured and applied to bridge structures. Weldless joints could for instance be manufactured with additive manufacturing or by casting, which are commonly used in the field of aviation.

\subsection{Difference Between the Eurocode and BSK}

The fatigue verification format contains essentially three components: the characteristic fatigue strength, the fatigue load and the safety factors.

The characteristic fatigue strength is determined in the same way in the Eurocode as in BSK. However, BSK is an older standard compared to the Eurocode and as a result it is based on a smaller amount of test samples. Therefore, there are differences in the characteristic fatigue strength between them.

The main difference between the two standards stems from the effect of traffic volume. This leads to that the Eurocode predicts a much lower fatigue life than BSK for the bridge and traffic volume given in Sect. 4.1. Leander (2018) used traffic data collected from Swedish traffic between 2005 and 2009 to estimate the scatter in the current verification format and to propose new $\lambda$-factors better suited for Swedish traffic. By comparing the $\lambda$-factors proposed in Lean$\operatorname{der}(2018)$ to the current $\lambda$-factors, the Eurocode provides a non-conservative estimate of the effect of the traffic volume used for the bridge given in Sect. 4.1. Therefore, the results obtained from the Eurocode are closer to reality than the results in BSK, at least in terms of traffic volume.

The difference in safety factors had a negligible effect on the fatigue strength and load.

\section{Conclusions}

\subsection{Overview of Bridge Structures}

The most common way of composing the cross-section is to have the higher strength material in the flange plates and the lower strength in the web plate, over the span of the bridge. The lower flange is more common to have a higher strength compared to the upper flange. This is most likely because of one or several of the following reasons: during construction, if unstiffened, the upper flange might be susceptible to buckling/later-torsional buckling and during operation the upper flange is usually exposed to far lower stresses than the lower flange, especially in composite structures. For the continuous bridges over the support area almost the same trend, as previously described, can be observed; with the higher strength steels in the flanges and the lower in the web plate. However, in this case the steel grade is usually the same in the upper and lower flange. Hybrid girders are usually the most economical way of composing steel girders (Mela and Heinisuo 2014; Horton et al. 2002; Barker and Schrage 2000). So there is no wonder that hybrid girders have gained in popularity and is today preferred over homogeneous girders.

\subsection{Fatigue Evaluation of Existing HSS Bridges}

With today's standard for fatigue assessment, these four bridges would not be possible to build without increasing the cross-sectional area to reduce the stress range. With an increased cross-sectional area the utilization ratio of the steel, without changing the steel grade, would decrease and the economic benefit of using the higher strength steels would most likely be lost.

Acknowledgements Open access funding provided by Royal Institute of Technology. The funding for this project, provided by the Swedish Transport Administration (Trafikverket), NCC, ELU and SSAB, is gratefully acknowledged. BBT Project Number 2016-010. 


\section{Compliance with Ethical Standards}

Conflict of interest The authors declare that they have no conflict of interest.

Open Access This article is licensed under a Creative Commons Attribution 4.0 International License, which permits use, sharing, adaptation, distribution and reproduction in any medium or format, as long as you give appropriate credit to the original author(s) and the source, provide a link to the Creative Commons licence, and indicate if changes were made. The images or other third party material in this article are included in the article's Creative Commons licence, unless indicated otherwise in a credit line to the material. If material is not included in the article's Creative Commons licence and your intended use is not permitted by statutory regulation or exceeds the permitted use, you will need to obtain permission directly from the copyright holder. To view a copy of this licence, visit http://creativecommons.org/licenses/by/4.0/.

\section{References}

Azizinamini, A., Fallaha, S., \& Farimani, R. (2004). Outside the box. Civil Engineering, 74(9), 58-61.

Barker, M. G., \& Schrage, S. D. (2000). High-performance steel bridge design and cost comparisons. Transportation Research Record, $1740,33-39$.

Bjorhovde, R. (2004). Development and use of high performance steel. Journal of Constructional Steel Research, 60, 393-400.

Boverket. (1994). Boverkets handbok om stålkonstruktioner BRO 94. Stockholm: Boverket, byggavdelningen. (in Swedish)

Chen, S.-E., Boyajian, D., \& Scott, J. R. (2001). Hybrid high performance steel bridge on SR 1102 over I-77 in Iredell County. Raleigh: North Carolina Department of Transportation.

Croce, P. (2001). Background to fatigue load models for Eurocode 1: Part 2 traffic loads. Progress in Structural Engineering and Materials, 3, 335-345.

European Committee For Standardization (CEN). (2004a). SS-EN 10025-4: Eurocode-Hot rolled products of structural steels. Brussels: CEN.

European Committee for Standardization (CEN). (2004b). SS-EN 10025-6: Eurocode-Hot rolled products of structural steels: Part 6-Technical delivery conditions for flat products of high yield strength structural steels in the quenched and tempered condition. Brussels: CEN.

European Committee for Standardization (CEN). (2005). EN 1994-2: Eurocode 4-Design of composite steel and concrete structures: Part 2-General rules and rules for bridges. Brussels: CEN.

European Committee for Standardization (CEN). (2006). EN 1993-2: Eurocode 3-Design of steel structures: Part 2-Steel bridges. Brussels: CEN.

European Committee for Standardization (CEN). (2008). EN 1993-19: Eurocode 3-Design of steel structures: Part 1-9-Fatigue. Brussels: CEN.

European Committee for Standardization (CEN). (2010). EN 19912: Eurocode 1-Actions on structures: Part 2-Traffic loads on bridges. Brussels: CEN.
Günther, H., Raoul, J., Kuhlmann, U., Lwin, M., Wilson, A. D., Mistry, V. C., et al. (2005). Use and application of high-performance steels for steel structures. Zürich: IABSE-AIPC-IVBH.

Hobbacher, A. F. (2016). Recommendations for fatigue design of welded joints and components. London: International Institute of Welding.

Horton, R., Power, E., Ooyen, K. V., \& Azizinamini, A. (2002). Highperformance steel cost comparison study. Transportation Research Record, 1814, 27-36.

Johansson, B., Collin, P., Eriksen, J., Kuhlmann, U., Braun, B., Feldmann, M., et al. (2008). COMBRI design manual part II: Stateof-the-art and conceptual design of steel and composite bridges. Stuttgart: Universität Stuttgart.

Kirkhope, K., Bell, R., Caron, L., Basu, R., \& Ma, K.-T. (1999). Weld detail fatigue life improvement techniques. Part 1 -Review. Marine Structures, 12, 447-474.

Leander, J. (2018). Reliability evaluation of the Eurocode model for fatigue assessment of steel bridges. Journal of Constructional Steel Research, 141, 1-8.

Mela, K., \& Heinisuo, M. (2014). Weight and cost optimization of welded high strength steel beams. Engineering Structures, 79, 354-364.

Miki, C., Homma, K., \& Tominaga, T. (2002). High strength and high performance steels and their use in bridge structures. Journal of Constructional Steel Research, 58, 3-20.

Park, J., Chun, Y.-H., \& Lee, J. (2016). Optimal design of an arch bridge with high performance steel for bridges using genetic algorithm. International Journal of Steel Structures, 16, 559-572.

Sedlacek, G., Merzenich, G., Paschen, M., Bruls, A., Sanpaolesi, L., Croce, P., et al. (2008). Background document to EN 1991-Part 2: Traffic loads for road bridges-and consequences for the design. Report: JRC Science and Technology.

Trafikverket. (2004). Trafikverket, BaTMan, bro och tunnel management, v 7.1.2. Sweden: Trafikverket; 2004 [cited March 2017]. Retrieved March 2017 from https://batman.vv.se. (in Swedish).

Trafikverket. (2011). Trafikverkets tekniska krav Bro TRVK Bro 11. Borlänge: Trafikverket. (in Swedish).

Trafikverket. (2017). Vägtrafikfödeskartan. Sweden: Trafikverket; [cited November 2017]. Retrieved November 2017 from http:// vtf.trafikverket.se. (in Swedish).

Tsujii, M., \& Kanno, R. (2010). Advances in steel structures and steel materials in Japan. Tokyo: Nippon steel \& Sumitomo Metal.

Vägverket. (1994). Allmän teknisk beskrivning för broar BRO 942. Lastförutsättningar. Borlänge: Vägverket.

Yoneyama, T., \& Fujii, Y. (2015). Fabrication and erection of Tokyo gate bridge. In Proceedings of the IABSE-JSCE joint conference on advances in bridge engineering-III (pp. 268-277).

Publisher's Note Springer Nature remains neutral with regard to jurisdictional claims in published maps and institutional affiliations. 